\title{
Performance Data from the NIST Net-Zero Energy Residential Test Facility
}

\author{
William M. Healy, A. Hunter Fanney, Brian P. Dougherty, Lisa Ng, Vance Payne, Tania Ullah, Farhad Omar
}

Energy and Environment Division

Engineering Laboratory

National Institute of Standards and Technology

Gaithersburg, MD 20899

william.healy@nist.gov

hunter.fanney@nist.gov

brian.dougherty@nist.gov

lisa.ng@nist.gov

vance.payne@nist.gov

tania.ullah@nist.gov

farhad.omar@nist.gov

Data DOI: https://doi.org/10.18434/T46W2X

Key words: buildings; data; efficiency; energy; heating and cooling equipment; net-zero; photovoltaics; residential; ventilation; water heating.

Accepted: January 12, 2017

Published: January 17, 2017

https://doi.org/106028/jres.122.014

\section{Summary}

Data were collected over two separate year-long test periods at the Net-Zero Energy Residential Test Facility, a laboratory designed to evaluate a variety of technologies and operational strategies that lead to energy efficient houses with comfortable and healthful indoor environments. In a net-zero energy building, all energy consumption over the course of a year is offset by on-site renewable energy production; this facility attempts to meet that goal through use of a photovoltaic array installed on the roof. Data are presented for one-year test periods over which the research team examined whether the facility would reach net-zero status. In both years, the house was operated in an all-electric configuration, with slight modifications made in the second year related to control schemes and equipment selection. A virtual family of four was simulated to carry out the operations that would typically occur in a home (e.g., appliance usage, lighting usage, hot water usage). Data are being released for the second year of operation at the time of publication of this document, with an expectation that data from the first year will be released at a later date.

Data are captured as a time series where one data element is acquired every minute from each of 379 parallel data channels; these channels record a variety of quantities that are critical to evaluating the performance of the building. Among those quantities are: room temperatures, room relative humidities, electricity consumption by various devices, photovoltaic energy generation, outdoor conditions, operational status of devices, water temperatures, water flow rates, and airflow rates. Specifications are provided to fully describe the facility and its components, and an accompanying link provides design drawings and a data dictionary with key metadata for each of the channels. 


\section{Data Specifications}

\begin{tabular}{|l|l|}
\hline NIST Operating Unit(s) & Engineering Laboratory; Energy and Environment Division \\
\hline Format & Text (Comma Separated Values) and JavaScript Object Notation (JSON) \\
\hline Instrument & Net-Zero Energy Residential Test Facility \\
\hline $\begin{array}{l}\text { Spatial or Temporal (ISO 8601) } \\
\text { Elements }\end{array}$ & $\begin{array}{l}\text { Spatial: (Latitude, Longitude) }=\left(39.1^{\circ},-77.2^{\circ}\right) \\
\text { Temporal: 2015-02-01 through 2016-01-31 }\end{array}$ \\
\hline Data Dictionary & https://pages.nist.gov/netzero/data.html\#data_dictionary \\
\hline Accessibility & $\begin{array}{l}\text { All datasets submitted to Journal of Research of NIST are publicly } \\
\text { available. }\end{array}$ \\
\hline License & https://www.nist.gov/director/licensing \\
\hline
\end{tabular}

\section{Methods}

In 2012, the National Institute of Standards and Technology (NIST) completed construction of the Net-Zero Energy Residential Test Facility (NZERTF), a testbed designed as a single family house for use in developing measurement science for assessing equipment and strategies for achieving energy efficient homes with good indoor environmental quality [1]. After extensive instrumentation and planning, NIST began a one-year test period on July 1, 2013, to assess whether the building could achieve net-zero operation, meaning that the amount of energy consumed by the home over the course of a year would be less than that generated by the photovoltaic (PV) system located on the roof of the facility. The house was operated in an all-electric configuration with a simulated family of four carrying out activities that would be expected in a typical American household. The home achieved net-zero status during this year of monitoring, with the PV system generating $13523 \mathrm{kWh}$ of electricity compared to the $13039 \mathrm{kWh}$ consumed [2]. Following that first year of operation, NIST embarked on a second year of operation starting on February 1, 2015, after making changes to certain operational control schemes. Year 2 results showed an improvement over Year 1, with the annual net energy returned to the electrical power grid increasing from $484 \mathrm{kWh}$ to $2240 \mathrm{kWh}$. This increase in net energy to the grid largely arose because of lower energy consumption, as the electricity generated from the photovoltaic array was very similar for the two years [3].

NIST, in conjunction with the U.S. Department of Commerce Data Service, is making available data from the operation of the facility during these two test years at https://pages.nist.gov/netzero/ [4]. The data from the second year of operation is being released first. Data from Year 1 will be released after the Year 2 data are published and feedback is gained on the effectiveness of the dataset and the accompanying explanatory information.

Data were recorded on a minutely basis from a range of sensors that monitored electricity usage, equipment performance, indoor conditions, and outdoor conditions. Data also indicate whether or not loads were activated as well as the amount of heat that each load introduced into the space. While every effort was made to minimize disruptions in data flow, there were times during the test phase when data were not available or particular subsystems within the house were not operating properly. A log of such instances is maintained on the website where the data can be accessed. The dataset for Year 2 has fewer data gaps and operational anomalies than Year 1, which contributed to the decision to make Year 2 data available first. The datasets for Years 1 and 2 contain minutely entries for $98.5 \%$ and $98.8 \%$ percent, respectively, of the annual maximum total of 525600 minutely entries. In addition to the minutely data, the values are compiled on an hourly basis to provide the data in file sizes that are smaller than the full minutely data set. Each channel is converted to an hourly value by either averaging all data points, taking the final reading of the hour (e.g., in cases where each minute is a cumulative value of consumption), or summing all values for the hour. The manner in which the data are converted to hourly values is provided in the metadata file on the website.

The reader is referred to the resources listed in Table 1 for details on the construction and operation of the test facility. 
Table 1. Resources for further information on the NZERTF.

\begin{tabular}{|l|l|}
\hline General Information: & NZERTF website at http://www.nist.gov/el/nzertf/ [5] \\
\hline Design and construction specifications: & Pettit et al. 2014 [1], Kneifel 2012 [6] \\
\hline Architectural Plans: & NZERTF website at http://www.nist.gov/el/nzertf/ \\
\hline Simulation of occupancy and use: & Omar and Bushby 2013 [7] \\
\hline Measurement approaches employed in the facility: & Davis et al. 2014 [8] \\
\hline
\end{tabular}

The data website contains a data dictionary that includes two main parts. Part I of this data dictionary lists a table of characteristics of the NZERTF that are consistent with the taxonomy provided by the U.S. Department of Energy's Building Energy Performance Taxonomy, Version 2.1 [9]. Part 2 of the data dictionary provides a description of each of the 379 data channels available in the database. The Data Label gives the name assigned to each channel. Each of those channels is associated with a primary Subsystem: Domestic Hot Water (DHW), Solar Hot Water (SHW), Electrical and Thermal Loads (Loads), Heating and Cooling System (HVAC), Indoor Environment (IndEnv), Photovoltaic (PV), Outdoor Environment (OutEnv), Ventilation, Lighting, Electrical, and Instrumentation (Instr). The Instrumentation subsystem refers to equipment that would not normally be found in a house and so is not included in the determination of net energy operations. The Measurement Location of each measurement provides the place in the facility where the energy is consumed or the measurement is taking place. For example, while the heat pump provides conditioned air to the entire house, the primary measurements occur where the indoor unit is located, which is the basement. The Measured Parameter column groups the data by the primary measurement (e.g., Temperature, Energy, etc.) along with a more detailed description of that measurement type (e.g., Water vs. Air Temperature, Electrical vs. Thermal Energy). A Description of each data channel is provided along with the Units of the measurement.

\section{Test Configuration}

The test facility is equipped with a number of options for providing the services and amenities offered in a representative home. This section discusses the key aspects of the configurations in place for the first two years of testing.

\subsection{Year 1}

The key systems in place and operational schemes used during the first year of testing are shown in Table 2 .

Table 2. Configuration of NZERTF during Year 1.

\begin{tabular}{|l|l|}
\hline Heating and Cooling System & Air source heat pump \\
\hline Supplemental Dehumidification & $\begin{array}{l}\text { Air source heat pump that can operate in a dedicated dehumidification } \\
\text { mode, } 50 \% \text { RH setpoint }\end{array}$ \\
\hline Temperature Control Scheme & $\begin{array}{l}\text { Fixed setpoints in heating mode }\left(21^{\circ} \mathrm{C}\left[70^{\circ} \mathrm{F}\right]\right) \text { and cooling mode }\left(24^{\circ} \mathrm{C}\right. \\
\left.\left[75^{\circ} \mathrm{F}\right]\right) \text {; Generic wall-mounted thermostat }\end{array}$ \\
\hline Ventilation & Heat recovery ventilator \\
\hline Ventilation Control Scheme & Continuous at $170 \mathrm{~m}^{3} / \mathrm{h}(100 \mathrm{cfm})$ \\
\hline Water Heating System & Solar preheat with heat pump water heater backup - Two tank system \\
\hline Water Fixtures Used & Master bath shower, master bath tub, master bath sink, kitchen sink \\
\hline Simulated Occupancy & Two adults, two children \\
\hline Rated Photovoltaic Output & $10.24 \mathrm{~kW}$ \\
\hline Start Date & July 1,2013 \\
\hline End Date & June 30,2014 \\
\hline
\end{tabular}




\subsection{Year 2}

The key changes that occurred in the second test year included an alternative dehumidification approach, a modified ventilation control scheme, and a switch to a more user-configurable wall-mounted thermostat. Table 3 provides the configuration of the NZERTF in Year 2.

Table 3. Configuration of NZERTF during Year 2.

\begin{tabular}{|l|l|}
\hline Heating and Cooling System & Air source heat pump \\
\hline Supplemental Dehumidification & Whole-house dehumidifier, $50 \% \mathrm{RH}$ setpoint \\
\hline Temperature Control Scheme & $\begin{array}{l}\text { Fixed setpoints in heating mode }\left(21^{\circ} \mathrm{C}\left[70^{\circ} \mathrm{F}\right]\right) \text { and cooling mode }\left(24^{\circ} \mathrm{C}\right. \\
\left.\left[75^{\circ} \mathrm{F}\right]\right) \text {; More user-configurable wall-mounted thermostat }\end{array}$ \\
\hline Ventilation & Heat recovery ventilator \\
\hline Ventilation Control Scheme & $\begin{array}{l}\text { Intermittent: } 43 \text { minutes on during each hour, average airflow rate of } \\
140 \mathrm{~m}^{3} / \mathrm{h}(80 \mathrm{cfm})\end{array}$ \\
\hline Water Heating System & Solar preheat with heat pump water heater backup - Two tank system \\
\hline Water Fixtures Used & $\begin{array}{l}\text { Master bath shower, master bath tub, master bath sink, } 2^{\text {nd }} \text { floor bath } \\
\text { shower, } 2^{\text {nd }} \text { floor bath sink, kitchen sink }\end{array}$ \\
\hline Simulated Occupancy & Two adults, two children \\
\hline Rated Photovoltaic Output & $10.24 \mathrm{~kW}$ \\
\hline Start Date & February 1,2015 \\
\hline End Date & January 31,2016 \\
\hline
\end{tabular}

\section{Disclaimers}

The data provided are those measured from the sensors in the Net-Zero Energy Residential Test Facility. No efforts have been made to filter data or remove stray readings. Users should be aware that occasional problems occur with any sensing system and should therefore examine data for any anomalies and assess the validity of such data points. At times when no data are present from a particular instrument, an entry of "NA" is placed in the dataset. There may be other times when data are being recorded, but erroneous connections may result in a series of zeros in the dataset. Those values have not been removed, but the user is cautioned to be aware that they may exist in the dataset.

The experiment was monitored on a weekly basis to ensure that systems operated as planned, but inevitable experimental glitches occurred. Those glitches have been captured in a document included with the dataset. NIST is aware of several data gaps or operational anomalies that are reflected in the dataset for Year 2. The log provided in the "Known Data Gaps and Issues" section of the data website lists the known issues by the main subsystems: General, Solar, Ventilation, Indoor Air Quality (IAQ), Heat Pump, and Domestic Hot Water (DHW). Some of the key issues are as follows:

1) There were several occasions where sampling of the indoor air quality was taking place. During these occasions, blower fans for the central heat pump unit are maintained in the "On" position to assist in mixing the air, and additional instrumentation power and heat loads from the equipment are present. Those instances are noted in the IAQ section.

2) At the beginning of the year-long data collection period, some short term tests were conducted to evaluate the airflow measurement in the Heat Recovery Ventilator and to assess the transient response of the facility. These dates are noted in the "General," "Ventilation," and "Heat Pump" sections.

3) Snow cover of the solar panels is recorded in the "General and Solar PV Comments" section.

4) An incorrect setting of a valve on the solar thermal water heating system starting on February 19, 2015, and ending on March 17, 2015, caused a long stretch of operation without that system operational.

5) The heat pump unit was not working for approximately two days starting on May 30, 2015, due to the failure of a relay on the outdoor unit. 
6) Approximately three days of data are missing starting on October 20, 2015, due to a problem with the data acquisition and control system.

The experimental setup called for resets of the data acquisition system at midnight. This process occasionally took several minutes, so some data points are missing at the beginning or end of days. For that reason, the number of data entries for each day may vary, and that number is typically less than 1440 (the number of minutes in a day). As noted, minutes with missing data are filled in with "NA" across all channels.

\section{Impact}

It is expected that the datasets can be used to improve the understanding of the performance of efficient homes. Modelers of building energy performance can use the data to validate computer simulations and to develop input parameters for particular equipment that might be present in homes. Developers of novel devices and control schemes for homes could use the data to better understand conditions present in an energy efficient house. Educators can use the data as part of projects for students to help improve the understanding of building systems and operations.

\section{Acknowledgments}

The research team thanks Priyanka Oberoi, Jeff Chen, Mark Brown, Radhika Bhatt, and Laura McGorman of the Department of Commerce's Commerce Data Service, and Steve Barber, Tzong Hao Chen, and Andrew Mundy of the NIST Engineering Laboratory for their assistance in converting the measured data into a format appropriate for users and for developing the website that hosts the dataset.

\section{7. $\quad$ References}

[1] Pettit B, Gates C, Fanney AH, Healy W (2014) Design Challenges of the NIST Net Zero Energy Residential Test Facility (National Institute of Standards and Technology).

[2] Fanney AH, et al. (2015) Net-zero and beyond! Design and performance of NIST’s net-zero energy residential test facility. Energy Build 101:95-109.

[3] Fanney AH, et al. (2016) Small Changes Yield Large Results at NIST’s Net-Zero Energy Residential Test Facility.

[4] NIST Net-Zero Homepage Available at: https://pages.nist.gov/netzero/ [Accessed November 2, 2016].

[5] National Institute of Standards and Technology (2016) Net-Zero Energy Residential Test Facility (NZERTF). NIST. Available at: https://www.nist.gov/el/net-zero-energy-residential-test-facility [Accessed November 2, 2016].

[6] Kneifel J (2012) Annual Whole Building Energy Simulation of the NIST Net Zero Energy Residential Test Facility Design (National Institute of Standards and Technology, Gaithersburg, MD) Available at: http://nvlpubs.nist.gov/nistpubs/TechnicalNotes/NIST.TN.1767.pdf [Accessed July 13, 2016].

[7] Omar F, Bushby S (2013) Simulating Occupancy in The NIST Net-Zero Energy Residential Test Facility (National Institute of Standards and Technology) Available at: http://www.nist.gov/customcf/get_pdf.cfm?pub_id=914650 [Accessed April 3, 2014].

[8] Davis M, et al. (2014) Monitoring Techniques for the Net-Zero Energy Residential Test Facility (National Institute of Standards and Technology, Gaithersburg, MD).

[9] United States Department of Energy (2012) DOE Building Energy Performance Taxonomy. Available at: https://www1.eere.energy.gov/buildings/commercial/pdfs/doe_building_energy_performance_taxonomy.pdf [Accessed November 3, 2016].

About the authors: William Healy is the leader of the Heat Transfer and Alternative Energy Systems Group. A. Hunter Fanney is a Senior Research Scientist. Brian Dougherty and Tania Ullah are mechanical engineers in the Heat Transfer and Alternative Energy Systems Group. Lisa $\mathrm{Ng}$ is a mechanical engineer in the Indoor Air Quality and Ventilation Group. Vance Payne is a mechanical engineer in the HVAC\&R Equipment Performance Group. Farhad Omar is an electrical engineer in the Mechanical Systems and Controls Group. All authors are members of the Energy and Environment Division within the Engineering Laboratory. The National Institute of Standards and Technology is an agency of the U.S. Department of Commerce. 